\title{
Effectiveness of Oral Health Education on Oral Hygiene Knowledge, Practices of Lower Secondary School Children in Kathmandu District
}

\author{
Sunita Khanal,' Rosina Bhattarai, ${ }^{2}$ Sujita Shrestha, ${ }^{1}$ G.Nagaraja Rao ${ }^{3}$ \\ 'Department of Community and Public Health Dentistry, Kantipur Dental College, Basundhara, Kathmandu, ${ }^{2}$ Department of \\ Community and Public Health Dentistry, College of Medical Sciences, College of Medical Sciences, Bharatpur, Chitwan, \\ Nepal, ${ }^{3}$ Community and Public Health Dentistry.
}

\begin{abstract}
Introduction

An important goal of health system is health promotion and disease prevention. In order to enable people to develop personal skills in managing their own oral health, there is a recognized need to deliver oral health information to people during clinical encounters. To ensure positive, long term dental health and hygiene, good oral hygiene practices are necessary from young age. The present study was conducted to assess the effectiveness of oral health education on oral hygiene knowledge, practices of lower secondary school children in Kathmandu district.
\end{abstract}

\section{Methods}

A quasi -experimental study was conducted among lower secondary school children of Kathmandu district. Altogether 400 students participated in the study. Structured questionnaire was used for data collection purpose which contained 15 knowledge questions and 10 practice questions. The data was analysed by using SPSS version 20 software. Multiple linear regression analysis was used at $\leq 0.05$ level of significance.

\section{Results}

Altogether 400 students participated in all three visits of the study. The participants were divided into two experimental groups i.e. audio-visual and chart and model groups. The knowledge level increased in both the experimental groups after subsequent health education. Audio-visual method was found to be more effective in improving knowledge $(p \leq 0.001)$ and practice.

\section{Conclusions}

The oral health education was found to be effective in increasing oral healthrelated knowledge and practices of students.

Keywords: effectiveness; health education; knowledge.

Correspondance: Dr. Sunita Khanal, Department of Community and Public Health Dentistry, Kantipur Dental College, Basundhara, Kathmandu, Nepal. Email:- khanal.sunita729@gmail.com,Phone no: +977-9841830063. 


\section{INTRODUCTION}

For maintaining the good oral health of an individual, oral hygiene and diet plays a major role together. ${ }^{1}$ In improving the oral health knowledge and behaviour, school based oral healtheducation has been found effective. ${ }^{2}$ Health education is the process of transmission of skills and knowledge necessary for the improvement of quality of life. ${ }^{3}$ Untreated dental conditions and poor oral health can have significant impact on the quality of life of children which may lead to deterioration of health. ${ }^{4}$

Lack of oral health education and awareness program can be attributed factor for lack of knowledge and poor behaviour towards oral health. The school children of Nepal havelow level of oral health awareness and practice compared to their western counterparts. ${ }^{5}$ So, the objective of this study is to assess the "Effectiveness of Oral Health Education on Oral Hygiene knowledge, Practices of lower Secondary school Children in Kathmandu District"

\section{METHODS}

A quasi -experimental study i.e. pre-test posttest control design has been conducted to assess the basic dental knowledge and practices among lower secondary school going children i.e. students of grade six only. Same group of children had been educated and re assessed for their improvement of knowledge and practices by using two methods i.e. Chart and model method and audio-visual method. Ethical clearance was obtained from the institutional review board of Kantipur Dental College to conduct the study. Prior permission was obtained from the principal of the school and parents of grade six children before starting the study

Simple random sampling technique was used for school selection purpose. The list of schools in Kathmandu district were obtained from the internet and from that list, schools that were within one hour of reach from dental college were made and a lottery method was done. Based on student's population and consent from the school, three government and three private school were chosen for the study. Two government and two private schools were taken as an experimental school and one government and one private school as a control group.

Sample size was calculated at $f(\alpha, \beta)=80 \%$ power with $5 \%$ significance with $\mathrm{D}=(2.1)^{7}$ and $\mathrm{SD}=(3)^{7}$ The participants per group was calculated to be 40 after taking $25 \%$ non-response rate. ${ }^{8}$

Four hundred students were included in the study. Altogether six schools were selected for the study. Two different dental health education methods were used for experimental groups whereas control group did not receive any health education in the beginning. All the students of grade six who were present in all three visits and who were willing to participate in the study were included in the study.

The effectiveness of health education programs was evaluated by using the structured questionnaire. The questionnaire contained 15 knowledge questions and 10 practice questions. The questionnaire and scoring criteria was developed as per the references with the advice from experts involved with the research during the preparatory phase. For health education purpose single investigator was used for both the experimental groups. The investigator was trained before giving health education. The health education was prepared and was presented in front of the experts and was approved. Pretesting of questionnaire was done among 40 students who were not included in the final analysis. Cronbach's alpha value was found to be $>0.7$

During first visit, on the first day, questionnaires were given to assess the participant's baseline knowledge. On the second day oral health 
education was given for the experimental groups using two different methods. After three months again, on the first day, questionnaires were distributed to the same study population. Again on the second day oral health education was provided using two different methods according to the group allocation. After six months i.e. at final visit again questionnaires were given to the participants for their knowledge assessment. Only after collecting the data from all three visits the health education was provided to the control group.

The data was entered and coded in Microsoft excel. The data was then transferred to SPSS version 20 for further analysis. Multiple linear regression analysis was done at $\leq 0.05$ level of significance to assess the impact of health education

RESULTS
Among the total 400 students who participated in all three visits of the study, there were 160 students in the audio-visual method, out of which 76 were male and 84 were female.

There were 160 students in the chart and model method, out of which 86 were male and 74 were female. There were 80 students in the control group, out of which 34 males and 46 females were there. (Figure 1)

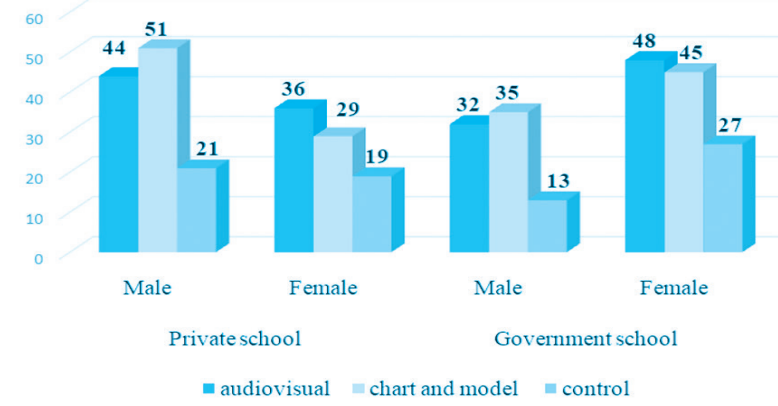

Figure 1. Showing the distribution of total population who participated in the study

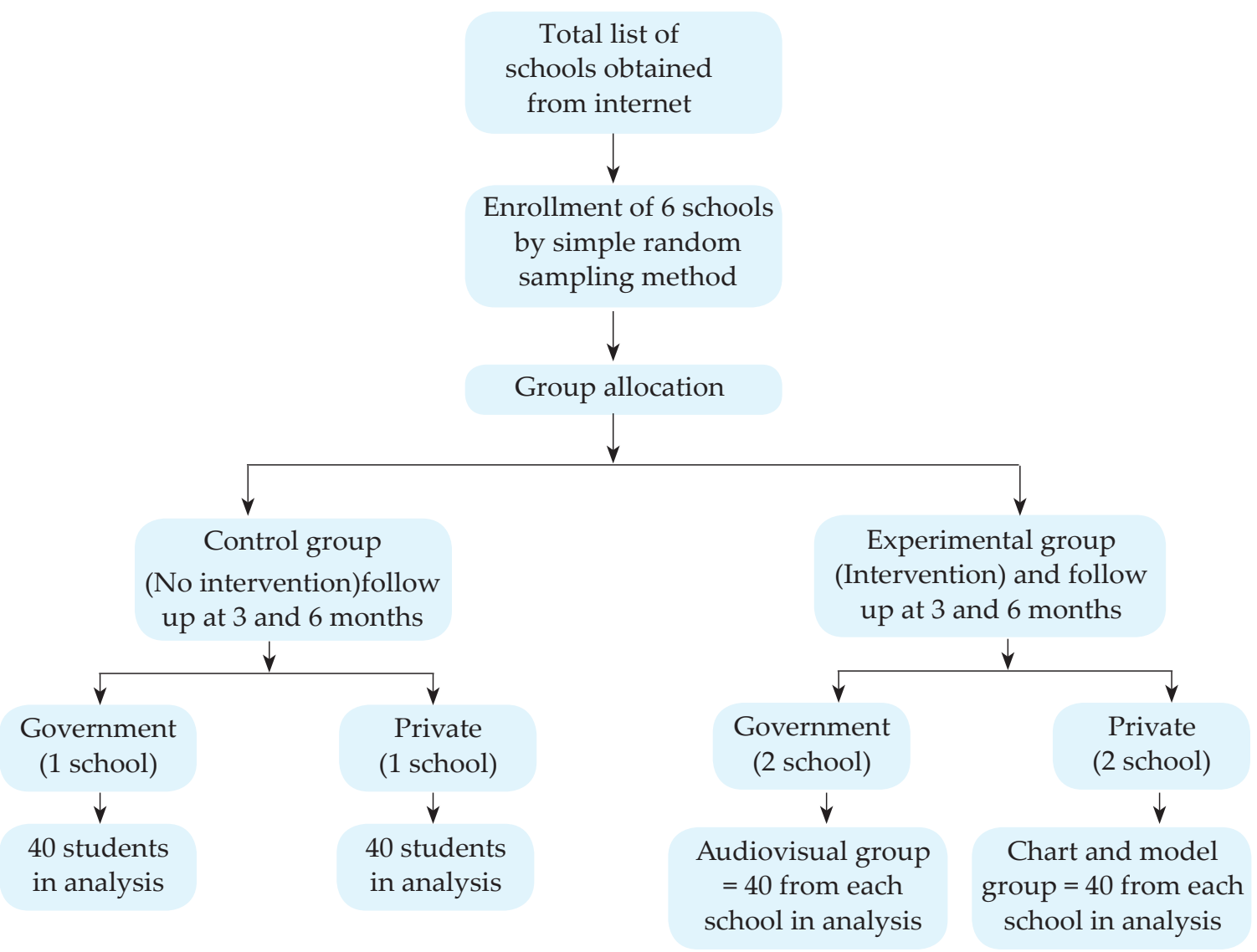

Flow Diagram 
Among government school students, (audiovisual group), in the first visit, mean score for knowledge questions in the males and females was $7.09 \pm 2.46$ and $7.90 \pm 2.33$ respectively and mean practice score was $7.59 \pm 2.046$ and $8.91 \pm 1.32$ respectively. Similarly, among private school students, in the first visit, the mean knowledge score among males and females was $9.57 \pm 2.028$ and $9.8 \pm 2.335$ and mean practice score was $8.52 \pm 1.045$ and $8.72 \pm 1.137$ respectively.

In the first visit, the mean knowledge score in government school males and females, (chart and model method) was 6.74 \pm 2.31 and $6.96 \pm 2.29$ respectively and mean practice score was $7.37 \pm 1.72$ and $7.47 \pm 1.75$ respectively. In the private school, in the first visit, the mean

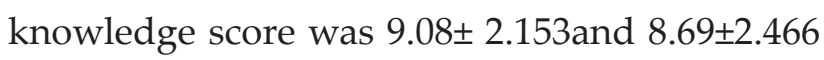
among males and females and mean practice score was $8.61 \pm 1.56$ and $8.45 \pm 1.27$ respectively. (Table 1)

Table 1. Showing the baseline knowledge and practice scores among government and private school students in the experimental group.

\begin{tabular}{|c|c|c|c|c|}
\hline & \multicolumn{3}{|c|}{ Knowledge scores } & \multirow{2}{*}{$\begin{array}{c}\begin{array}{c}\text { Practice } \\
\text { scores }\end{array} \\
\text { Mean } \pm S D\end{array}$} \\
\hline Methodology & School & Gender & Mean $\pm S D$ & \\
\hline \multirow{4}{*}{$\begin{array}{l}\text { Audiovisual } \\
\text { method }\end{array}$} & \multirow{2}{*}{$\begin{array}{l}\text { Government } \\
\text { school }\end{array}$} & Male & $7.09 \pm 2.46$ & $7.59 \pm 2.046$ \\
\hline & & Female & $7.90 \pm 2.33$ & $8.91 \pm 1.32$ \\
\hline & \multirow[t]{2}{*}{ Private school } & Male & $9.57 \pm 2.028$ & $8.52 \pm 1.04$ \\
\hline & & Female & $9.8 \pm 2.35$ & $8.72 \pm 1.14$ \\
\hline \multirow{4}{*}{$\begin{array}{l}\text { Chart and } \\
\text { model method }\end{array}$} & \multirow{2}{*}{$\begin{array}{l}\text { Government } \\
\text { school }\end{array}$} & Male & $6.74 \pm 2.31$ & $7.37 \pm 1.72$ \\
\hline & & Female & $6.96 \pm 2.29$ & $7.47 \pm 1.75$ \\
\hline & \multirow[t]{2}{*}{ Private school } & Male & $9.08 \pm 2.15$ & $8.61 \pm 1.56$ \\
\hline & & Female & $8.69 \pm 2.466$ & $8.45 \pm 1.27$ \\
\hline
\end{tabular}

The mean knowledge score of male and female in control group in first visit was $9.65 \pm 2.21$ and $9.57 \pm 2.42$ respectively and the mean practice score of male and female was $8.18 \pm 1.45$ and 7.83 \pm 1.73 respectively (Table 2 ).
Table 2. Showing the baseline knowledge and practice scores among government and private school students in the control group.

\begin{tabular}{|l|l|}
\hline Gender & Mean score \pm SD \\
\hline Knowledge score \\
\hline Male & $9.65 \pm 2.21$ \\
\hline Female & $9.57 \pm 2.419$ \\
\hline \multicolumn{2}{|c|}{ Practice score } \\
\hline Male & $8.18 \pm 1.445$ \\
\hline Female & $7.83 \pm 1.730$ \\
\hline
\end{tabular}

At baseline, control group had more knowledge compared to experimental groups. Due to audio-visual method only, the increase in knowledge was 0.87 in second visit and was statistically significant. In the third visit the knowledge further increased to 1.044 which was also statistically significant. Due to the chart and model method only, the increase in knowledge in second and third visit was 0.406 and 0.496 respectively which was statistically significant. Audio-visual method seemed to contribute to increase the knowledge score more after netting out improvements of score in control group i.e. doing nothing effect. So, it was proved to be the best method. (Table 3)

Table 3. change in mean knowledge scores in all examined groups using the multiple linear regression analysis.

\begin{tabular}{|l|c|c|c|}
\hline \multicolumn{1}{|c|}{ Parameters } & $\begin{array}{c}\text { Estimation } \\
(\beta)\end{array}$ & $\begin{array}{c}\text { Standard } \\
\text { error (S.E) }\end{array}$ & p-value \\
\hline Constant & 9.600 & 0.267 & \\
\hline Audiovisual & -1.137 & 0.327 & $<0.001^{*}$ \\
\hline $\begin{array}{l}\text { Chart and } \\
\text { model }\end{array}$ & -0.850 & 0.164 & $<0.001^{*}$ \\
\hline $\begin{array}{l}\text { Audiovisual } \\
\text { method 2 }\end{array}$ & 0.878 & 0.232 & $<0.001^{\text {nd }}$ vit \\
\hline $\begin{array}{l}\text { Chart and } \\
\text { model 2 }\end{array}$ & .406 & 0.116 & $<0.001^{\text {nd }}$ visit
\end{tabular}

*= statistically significant 
Due to audio-visual method only, the increase in practice score in second and third visit was 0.184 and 0.085 respectively which was not statistically significant. Due to chart and model method only, the increase in knowledge and practice in second and third visit was 0.19 and 0.029 respectively which was not statistically significant. (Table 4)

\begin{tabular}{|l|l|l|l|}
\hline $\begin{array}{l}\text { Table 4. Change in mean practice scores in all } \\
\text { examined groups using the multiple linear } \\
\text { regression analysis. }\end{array}$ \\
\hline \multicolumn{1}{|c|}{ Parameters } & $\begin{array}{c}\text { Estimation } \\
(\beta)\end{array}$ & $\begin{array}{c}\text { Standard } \\
\text { error }\end{array}$ & p value \\
\hline Constant & 7.975 & 0.152 & \\
\hline $\begin{array}{l}\text { Audiovisual } \\
\text { Chart and } \\
\text { model method }\end{array}$ & 0.175 & 0.186 & $0.348(N S)$ \\
\hline $\begin{array}{l}\text { Audiovisual } 2^{\text {nd }} \\
\text { visit }\end{array}$ & 0.184 & 0.132 & $0.162(N S)$ \\
\hline $\begin{array}{l}\text { Chart and } \\
\text { model } 2^{\text {nd }} \text { visit }\end{array}$ & 0.019 & 0.066 & $0.776(N S)$ \\
\hline $\begin{array}{l}\text { Audiovisual } 3^{\text {rd }} \\
\text { visit }\end{array}$ & 0.085 & 0.088 & $0.331(N S)$ \\
\hline $\begin{array}{l}\text { Chart and } \\
\text { model } 3^{\text {rd }} \text { visit }\end{array}$ & 0.029 & 0.044 & $0.507(N S)$ \\
\hline $\begin{array}{l}\text { Adjusted R } \\
\text { square value }\end{array}$ & 0.128 & & \\
\hline Total number & 400 & & \\
\hline
\end{tabular}

NS= Not Significant

\section{DISCUSSION}

Health is a fundamental human right and a common theme in most cultures without distinction of race, religion, and political belief, economic and social condition. ${ }^{6}$ Researches conducted in the past have shown health education to be effective in controlling and preventing various dental diseases. ${ }^{7,9}$

In the present study, overall knowledge score was greater in control group compared to experimental groups during first visit. Due to audio-visual method, the increase in knowledge was 0.87 in second visit and was statistically significant. In thethird visit the knowled gefurther increased to 1.044 which was also statistically significant. Due to the chart and model method, the increase in knowledge in second and third visit was 0.406 and 0.496 respectively which was statistically significant. These findings were similar to the study conducted by Hebbal, et al. ${ }^{3}$

Audio-visual method seemed to contribute to increase the knowledge score more after netting out improvements of score in control group i.e. doing nothing effect. So, it was proved to be the best method (Table number 1). This may be due to better clarification by audio-visual demonstration compared to chart and model method. Also educational videos in between the slides might have gained better attention. This finding was similar to other studies conducted by Hebbal Met al. Shah $\mathrm{N}$ et al.and Bennell FB. ${ }^{3,10,11}$

Experimental groups had better practices compared to the control group in all three visits which was not statistically significant. This may be due to hawthorne effect. In audio-visual method, the increase in practice score in second and third visit was 0.184 and 0.085 which was not statistically significant. Due to chart and model method, the increase in knowledge and practice in second and third visit was 0.19 and 0.029 which was not statistically significant. This finding was similar to the study conducted by D'Cruz and Aradhya. ${ }^{12}$ Compared to chart and model groups, audio-visual groups followed better practices after receiving health education. It may be due to the fact that while using the projected aids we can show videos showing adverse effects of bad oral practices. But in chart and model method we can only educate and show pictures to the students. Hence the teaching methodology might have affected the impact of health education and health education by audiovisual method was effective in increasing both 
knowledge and practice of students to a greater extent compared to chart and model method.

Since randomization has not been done chance of bias are always there. An inherent bias is that practice was measured as self-reported - an overreport of favourable behaviours might be there. Also there might be exchange of information between the different experimental groups.

The main limitation of the present study is that findings cannot be generalized to all students of Nepal, school personnel and teachers were not involved. They might have ensured enduring benefits after discontinuation of program. Also change in oral health status could have been added along with questionnaire for better representation of results.

\section{CONCLUSIONS}

The study provides clear evidence that repeated oral health education results in improved oral health knowledge and practices of children.

\section{ACKNOWLEDGEMENTS}

We are thankful to Prof. Dr. S. Bhattacharyya for his help, advice and suggestions during this research.

\section{REFERENCES}

1. Adeniyi A.A, Ogunbodede E.O, Jeboda S.O, Sofola O.O. Dental caries occurrence and associated oral hygiene practices among rural and urban Nigerian pre-school children. J Dent Oral Hyg. 2009;1(2014):64-70.

2. Worthington $\mathrm{H} \mathrm{V.,} \mathrm{Hill} \mathrm{KB,} \mathrm{Mooney} \mathrm{J,}$ Hamilton FA, Blinkhorn AS. A cluster randomized controlled trial of a dental health education program for 10-yearold children. J Public Health Dent. 2001;61(1):22-7.

3. Hebbal M, Vadavi D, Ankola A, Patel K. Evaluation of knowledge and plaque scores in school children before and after health education. Dent Res J (Isfahan). 2011;8(4):189-96.

4. Petersen PE. The World Oral Health Report 2003: Continuous improvement of oral health in the 21st century - The approach of the WHO Global Oral Health Programme. Community Dent Oral Epidemiol. 2003;31(SUPPL. 1):324.
5. Humagain M. Evaluation of knowledge, attitude and practice (KAP) about oral health among secondary level students of rural Nepal-a questionnaire study. Webcam Cent Dent. 2011;2(3):1-17.

6. Bhardwaj V, Jhingta P, Justa A, Luthra R, Sharma K, Sharma D. Impact of schoolbased oral health education program on oral health of 12 and 15 years old school children. J Educ Health Promot. 2013;2(1):33.

7. Hartono SWA, Lambri SE. Effectiveness of primary school- based oral health education in West Java, Indonesia. Int Dent J. 2002; 52(3):137-43

8. Kelley K, Clark B, Brown V, Sitzia J. Good practice in the conduct and reporting of survey research. Int J Qual Heal Care. 2003;15(3):261-6.

9. Wang NJ, Källestål C, Petersen PE, Arnadottir IB. Caries preventive services for children and adolescents in Denmark, Iceland, Norway and Sweden: strategies 
and resource allocation. Community Dent Oral Epidemiol. 1998; 26(4):263-71

10. Shah N, Mathur V, Kathuria V, Gupta T. Effectiveness of an educational video in improving oral health knowledge in a hospital setting. Indian J Dent. 2016;7(2):70-75.

11. Bennell FB. Audio-Visual Aids in Health
Education. J Sch Health. 1957;27(1): 21-5.

12. D'CruzAM, Aradhya S. Impact of oral health education on oral hygiene knowledge, practices, plaque control and gingival health of 13- to 15-year-old school children in Bangalore city. Int J Dent Hyg. 2013;11(2):126-33.

Citation: Khanal S, Bhattarai R, Shrestha S, Rao G. Effectiveness of Oral Health Education on Oral Hygiene Knowledge, Practices of Lower Secondary School Children in Kathmandu District. JCMS Nepal. 2020; 16(4):215-21. 